\title{
Study on Machining Parameters for Thrust Force and Torque in Milling AA7039 Composites Reinforced with $\mathrm{Al}_{2} \mathrm{O}_{3} / \mathrm{B}_{4} \mathrm{C} / \mathrm{SiC}$ Particles
}

\author{
Sener Karabulut \\ Department of Mechanical Program, Hacettepe University, 06935 Ankara, Turkey. \\ (senerkarabulut@hacettepe.edu.tr)
}

‡Corresponding Author; Department of Mechanical Program, Hacettepe University, 06935 Ankara, Turkey, Tel: +90 312267

30 20, Fax: +90312 26733 38, senerkarabulut@ hacettepe.edu.tr

Received: 20.05.2016 Accepted: 06.06.2016

\begin{abstract}
Metal matrix composites are used in many industrial fields such as automobile, military and aerospace applications due to their superior mechanical properties. In the present study, three aluminum 7039 metal matrix composite (MMCs) samples reinforced with $10 \mathrm{wt} . \%$ particulates of aluminum oxide $\left(\mathrm{Al}_{2} \mathrm{O}_{3}\right), 10 \mathrm{wt} . \%$ boron carbide $\left(\mathrm{B}_{4} \mathrm{C}\right)$, and $10 \mathrm{wt} . \%$ silicon carbide ( $\mathrm{SiC}$ ) were successfully fabricated using a powder metallurgy and hot extrusion method. The influences of cutting parameters on the thrust cutting force and torque during milling of the three MMCs were investigated under dry machining conditions. The milling tests were performed based on the Taguchi orthogonal -array design of experiments, $L_{27}\left(3^{4}\right)$ for different machining parameters such as cutting speed, feed and depth of cut. The effect of reinforcement contents on cutting force and torque were specified by utilizing analysis of variance (ANOVA). Mathematical models have been generated for the thrust force and torque through regression method. The results indicated that the minimal thrust force and torque were obtained in the machining of the $\mathrm{Al}_{2} \mathrm{O}_{3}$ reinforced specimen. The cutting force was directly influenced by the cutting feed and the axial cutting depth was the most effective machining parameter affecting milling torque in the machining of three composite specimens. The experimental results were modeled using regression analysis and artificial neural networks (ANN) to predict the thrust force and torque. The thrust force and torque were predicted with a mean squared error equal to 5.85\% and 5.12\% respectively using ANN models.
\end{abstract}

Keywords: $\mathrm{AA} 7039, \mathrm{Al}_{2} \mathrm{O}_{3} / \mathrm{B}_{4} \mathrm{C} / \mathrm{SiC}$, thrust force, torque, milling.

\section{Introduction}

In recent years, Aluminum based MMCs are being attractive materials in a variety of engineering applications such as automobile products, aerospace parts and armor because of their excellent mechanical and thermal properties. The different types of reinforcement ceramic particles are used to improve the mechanical properties of the aluminum alloys. Many researchers are preferred the $\mathrm{Al}_{2} \mathrm{O}_{3}, \mathrm{~B}_{4} \mathrm{C}$ and $\mathrm{SiC}$ particles as reinforcement element for their superior mechanical properties. On the other hand, the implementations of MMCs are restricted in a very specific industry due to high fabrication cost and their poor machinability [1-3]. Milling is one of the most common machining process for the desired form and size by removing material in industry. Milling operations are carried out to produce 3 dimensional complex shapes products for aerospace, automotive parts, mold and die at high quality using advanced high speed machining technologies. Despite the improving machining technologies, machining software, $\mathrm{CNC}, \mathrm{CAD} / \mathrm{CAM}$ and cutting tool performances, the milling operations are still limited due to the high cutting forces and machining stabilities [4]. The determination of optimum machining parameters, proper cutting tool material and geometry for ideal cutting forces must be considered to meet the increasing productivity demands and reliable machining. Determination of the amplitude and frequency of the cutting force and torque are the most important key parameter in machining process in order to design of mechanical structure of machine tool, machine tool components, bearings, jigs, spindle and feed drive mechanisms, power consumption, tool life and productivity based on physical constraints [5]. Many researchers have been studied on metal cutting with different points of view for over hundred years and developed a several theories for cutting forces. One of the most popular theory was established by Merchant based on the minimum power consumption. The relationships among the forces 
acting on the chip during orthogonal cutting and machining parameters were formulated by Merchant. According to the Merchant's theory, the cutting speed is always constant, the tool cutting edge remains sharp during the cutting process and there is no built-up edge (BUE) constitution on the cutting insert [6]. Lee and Shaffer analyzed the process of orthogonal machining and they were theorized that the workpiece material on the cutting tool behaved as an ideal plastic metal and the chip was separated from the workpiece at the shear plane [7]. Several researchers are also investigated the cutting forces during machining MMCs. Kannan et al. [8] machined the MMCs orthogonally under different machining conditions to determine the effect of varying particulate size and volume fraction of $\mathrm{Al}_{2} \mathrm{O}_{3}$ particles on the plastic deformation behavior of matrix and correlation with cutting forces. They reported that the particle size and volume fraction were affected the deformation properties and cutting forces were indicated a correlation with the plastic deformation of MMCs. Ozcatalbas [9] investigated the influence of different amounts of $\mathrm{Al}_{4} \mathrm{C}_{3}$ reinforcements, depending on mechanical alloying on cutting forces, chip formation and surface roughness. High volume fraction of $\mathrm{Al}_{4} \mathrm{C}_{3}$ in the structure reduced the BUE formation resulted in lower cutting forces and shortened the chip contact length. Palanikumar and Muniaraj [10] performed an experimental study to determine the effect of drilling parameter on thrust force in machining Al6061 based MMCs. The experimental result showed the feed rate was the most significant machining parameter on the thrust force in drilling of hybrid MMCs. Many researchers have been reported to the BUE creation during machining of MMCs at lower machining speeds. Hence, the cutting force at lower cutting speed is lower compared with the higher machining speed. The feed rate and depth of cut have also significant effect on cutting forces. High cutting forces were observed in machining of MMCs due to the creation of voids around the reinforcement ceramic particles in the matrix structure [11-14]. The artificial neural networks are used in many different applications of MMCs including prediction of surface roughness, cutting force and cutting tool wear. The use of ANNs provides an easy methodology to solve the problems and has become increasingly popular in machining studies due to the ability to learn limited number of experimental results. Das et al. [15] studied on the machinability of $\mathrm{Al}-4.5 \% \mathrm{Cu} / \mathrm{TiC}$ MMCs and an ANN model was generated to estimate the cutting force in the milling of MMCs. experimental results indicated that cutting forces are comparatively higher in milling $\mathrm{Al}-4.5 \mathrm{Cu}-\mathrm{SiC}$ composites as compared to those for $\mathrm{Al}-4.5 \mathrm{Cu}-\mathrm{TiC}$ composites. The predicted values have shown a good correlation with the measured experimental values with the minimum error. Karabulut and Güllü [16] studied the machinability of the compacted graphite cast iron under different cutting conditions. Authors were investigated the influence of the entering angle on the cutting forces and prediction models for cutting forces were developed using artificial neural networks (ANN). The cutting forces were reduced with the increasing entering angles at all cutting conditions and the predicted cutting forces based on the ANN model had a good correlation with the measured data. Hiremath et al. [17] studied the influence of the reinforcement particle size on cutting forces in machining of MMCs. They reported that the cutting forces were reduced with increase in cutting speed feed rate and cutting depth. Hayajneh et al. [18] investigated the drilling behavior of aluminum based alumina/graphite hybrid metal matrix composite and investigated the machining parameters on the cutting force and torque. The effect of cutting parameters and volume fraction of the reinforced particles on the thrust force and torque were modeled using ANN. The prediction results were indicated to be in a very good correlation with the experimental results

The purpose of this study is to determine the effect of $\mathrm{B}_{4} \mathrm{C}, \mathrm{Al}_{2} \mathrm{O}_{3}$, and $\mathrm{SiC}$ reinforcement particles on the thrust force and torque under different machining parameters. Machining performance of the composites during milling was evaluated to remove a unit volume of metal with respect to cutting forces and torque. The influence of reinforcement elements and milling parameters for the thrust force and torque were determined. The microstructure of specimens and cutting tool surfaces were analyzed using optical microscopy and scanning electron microscopy (SEM). The results were analyzed by analysis of variance and prediction models for optimal milling parameters were specified.

\section{Experimental Methods and Analyses}

\subsection{Workpiece Material}

The milling experiments were performed on three different aluminum 7039 based composite materials. Experimental samples reinforced with $10 \mathrm{wt} . \% \mathrm{~B}_{4} \mathrm{C}, 10 \mathrm{wt} . \%$ $\mathrm{Al}_{2} \mathrm{O}_{3}$, and 10 wt.\% $\mathrm{SiC}$ were fabricated by a powder metallurgy (PM) and hot extrusion method (HEM). Aluminum 7039, $\mathrm{B}_{4} \mathrm{C}, \quad \mathrm{Al}_{2} \mathrm{O}_{3}$ and $\mathrm{SiC}$ powders were separately mixed and blended for $60 \mathrm{~min}$ in a threedimensional Turbula mixer to achieve a uniform particle distribution in matrix structure. After that, the mixed compositions were cold compacted at $300 \mathrm{MPa}$ and sintered at $550^{\circ} \mathrm{C}$ for $1 \mathrm{~h}$, thereby increasing hardness and strength. In the next step composites were extruded using a pre-heated extrusion mold to achieve a high degree of densification in the resulted product. After the extrusion process, the experimental specimens were solution heat-treated at $470^{\circ} \mathrm{C}$ for $2 \mathrm{~h}$ and then quenched in water at room temperature. Finally, the specimens were aged at $120{ }^{\circ} \mathrm{C}$ for $2 \mathrm{~h}$ in a furnace. Chemical compositions and microstructures of the specimens were determined using a JEOL JSM-6060LV scanning electron microscopy (SEM). Hardness tests were performed at different regions utilizing a EMCO-TEST Duravision 200 Vickers hardness testing machine. Chemical composition of aluminum 7039 and the average hardness values of the specimens are presented in Table 1 and Table 2, respectively.

Table 1. Chemical compositions of aluminum 7039

\begin{tabular}{lllllllll}
\hline \multicolumn{1}{c}{ Chemical composition (wt.\%) } \\
\hline $\mathrm{Al}$ & $\mathrm{Mg}$ & $\mathrm{Zn}$ & $\mathrm{Cu}$ & $\mathrm{Si}$ & $\mathrm{Mn}$ & $\mathrm{Ti}$ & $\mathrm{Fe}$ & $\mathrm{Cr}$ \\
89.91 & 4.17 & 4.39 & 0.53 & 0.45 & 0.2 & 0.19 & 0.12 & 0.02 \\
\hline
\end{tabular}

Table 2. Hardness of composite specimens (Hv)

\begin{tabular}{lll}
\hline 10 wt. $\% \mathrm{Al}_{2} \mathrm{O}_{3}$ & 10 wt.\% $\mathrm{B}_{4} \mathrm{C}$ & 10 wt.\% $\mathrm{SiC}$ \\
\hline 142 & 129 & 101 \\
\hline
\end{tabular}




\subsection{Machining Experiments}

The milling tests were performed on a three-axis CNC milling machine using uncoated carbide inserts under dry machining environment. A single Walter LNGX130708RL88, WK10 grade carbide insert was mounted on the ISO code F4041.B16.040.Z03.13 tool holder and a fresh cutting tool was used for every cutting force experiment. In literature, several researchers were recommended polycrystalline diamond (PCD) inserts because of their extremely hardness, wear resistance, abrasion and fracture resistance in machining of MMCs. On the other hand, PCDs are fairly low portion among the cutting tool materials due to the machining costs. Hence, carbide cutting inserts were used instead of PCDs in milling experiments [2]. The cutting parameters were chosen based on the cutting-toolmanufacturer recommendations, previous studies and preliminary experiments. The experimental cutting factors and their levels used in tests are depicted in Table 3. The torque and thrust force components in feed (Fy), tangential $(\mathrm{Fx})$ and radial $(\mathrm{Fz})$ directions generated during the milling tests were measured by utilizing a Kistler 9257B 3component dynamometer and Kistler 5070A amplifier Experimental setup and the directions of the cutting forces are illustrated in Fig.1 (a). All the measured cutting force signals were saved to a computer and evaluated with the help of Dynoware software at the end of the tests.

The cutting forces applied the workpiece to remove the chip by cutting insert can be separated into two categories as friction force and normal force to friction. The resultant force oriented at the friction angle $\beta$ can be obtained vectorial. There are also two cutting force components, shear force $F s$ and normal force to shear $F n$, acting on the removing chip. The resultant force, $F_{\mathrm{r}}$, and normal force, $F_{\mathrm{n}}$, were computed with the equations $F_{\mathrm{n}}=\sqrt{F_{y}^{2}+F_{z}^{2}}$ and, $F_{\mathrm{r}}=\sqrt{F_{\mathrm{n}}^{2}+F_{z}^{2}}$ where $F_{y}$ is the force in the feed direction, $F_{x}$ is the force in the $x$ direction and $F_{z}$ is the radial force. The cutting forces and thrust force are also depicted in Fig.1 (b).

The down-milling method was employed in the experiments due to the direction of cutter rotation and cutting feed is same. In down milling method, the cutting tool are begun with the maximum chip thickness and reaching zero at the end of the cut. Therefore, the cutting forces are in tendency to pull the specimen into the cutter and holding the insert in the machining. The experiments were conducted based on the Taguchi orthogonal-array design of experiments, $L_{27}\left(3^{4}\right)$ to reduce the total number of tests. time, cost and to measure data uniformly from within the range of the determined studying area.

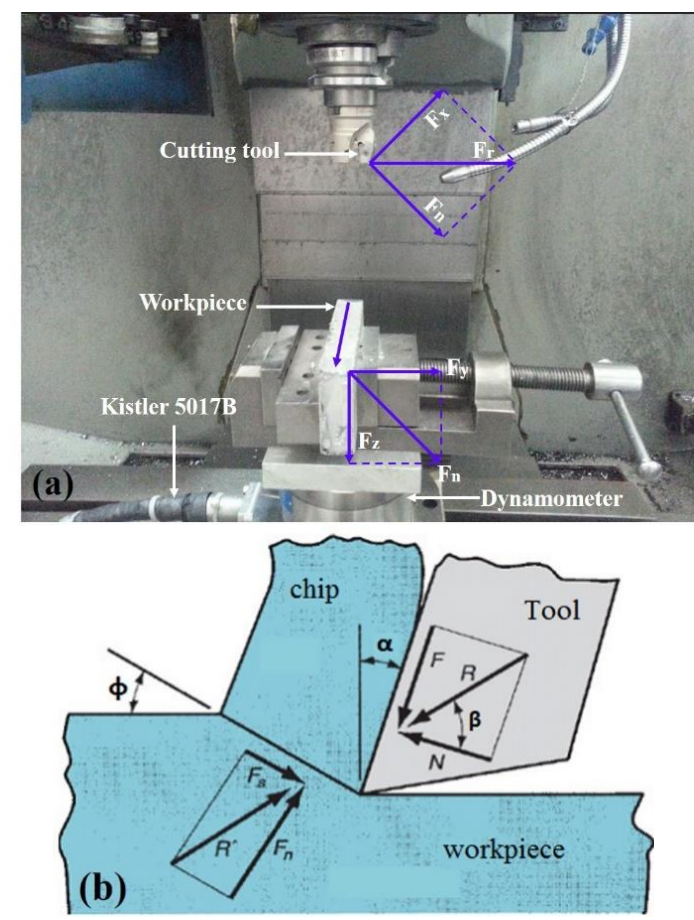

Fig.1 Experimental milling setup for cutting force and torque (a) measurement, (b) forces acting on the chip in orthogonal cutting

\section{Experimental Results and Discussion}

In the present study, three AA7039 based reinforced with 10 wt. $\% \mathrm{~B}_{4} \mathrm{C}, 10$ wt. $\% \mathrm{Al}_{2} \mathrm{O}_{3}$, and 10 wt. $\%$ SiC composites were successfully fabricated and studied the microstructural properties to determine the particle distribution in matrix. The optical image of surface texture of these composites and the particle distribution in matrix structure are depicted in Fig.2 (a), (b) and (c). As shown these figures, homogenous particle distributions were observed within the matrix structure as a result of the hot-extrusion fabrication route and the blending system. The milling experiments were performed for aluminum 7039 based MMCs and the influence of machining variables on cutting trust forces and cutting torques are presented in Figs. 3 and 4, respectively.

Table 3. The experimental milling parameters and the Taguchi $L_{27}\left(3^{4}\right)$ test levels

\begin{tabular}{llllll}
\hline Factor & Notation & Unit & Level 1 & Level 2 & Level 3 \\
\hline A-Material & $M$ & pieces & $10 \mathrm{wt} \% \mathrm{Al}_{2} \mathrm{O}_{3}$ & $10 \mathrm{wt}$ \% $\mathrm{B}_{4} \mathrm{C}$ & $10 \mathrm{wt} . \% \mathrm{SiC}$ \\
B-Cutting speed & $V_{c}$ & $\mathrm{~m} / \mathrm{min}$ & 290 & 375 & 488 \\
C-Cutting feed & $f_{z}$ & $\mathrm{~mm} / \mathrm{tooth}$ & 0.10 & 0.13 & 0.17 \\
D-Axial cutting depth & $a_{p}$ & $\mathrm{~mm}$ & 0.8 & 1.0 & 1.3 \\
Cutting width & $a_{e}$ & $\mathrm{~mm}$ & 24 & \\
Tool holder diameter & $D_{c}$ & $\mathrm{~mm}$ & 10 & \\
Number of cutting & $Z_{n}$ & pieces & & \\
edge & & $\mathrm{mm}^{3}$ & & & \\
Workpiece dimension & & & & \\
\hline
\end{tabular}



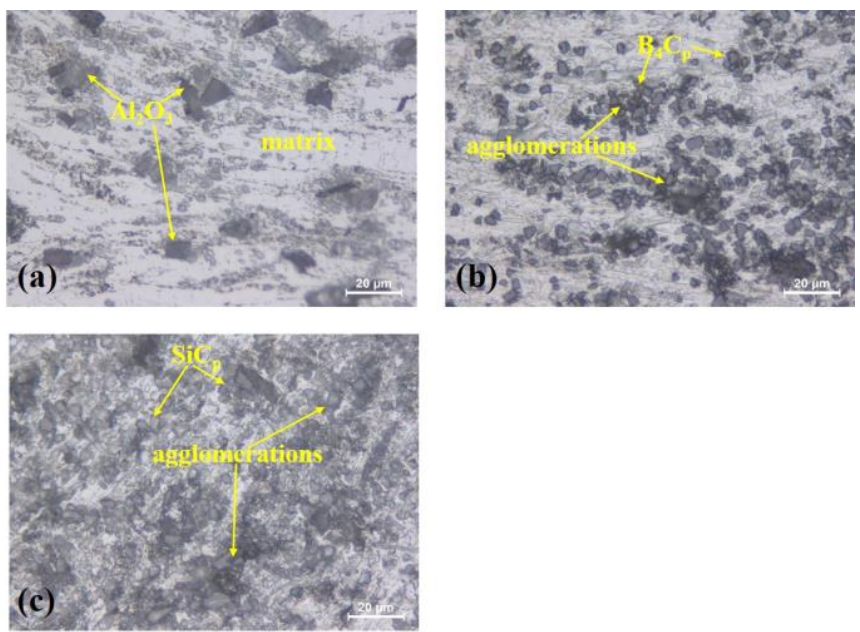

Fig. 2 Microstructures of (a) AA7039/ $\mathrm{Al}_{2} \mathrm{O}_{3}$, (b) AA7039/ $\mathrm{B}_{4} \mathrm{C}(\mathrm{b})$, and (c) AA7039/SiC.

As shown in three dimensional response surface graphs, increasing the feed rate and cutting depth results an increase in thrust force in the machining of all specimens. The thrust force was greatly affected with an increase in cutting feed due to the more chip was removed. The rise in axial depth of cut was also caused an increase in thrust force because the axial depth of cut was affected the width of the contact area in the table feed direction. This led to an increase in the load at high cutting depth influencing the cutting insert. Fig. 3 shows the influence of machining parameters on the thrust force. From the figures, it can be concluded that the thrust force is higher at lower cutting speed and decreased with the increase of cutting speed. The lower values of the thrust force are due to the reducing interface friction between cutting insert and workpiece in high cutting speeds. The machining speed effects the strength of the workpiece in the plastic deformation area through increasing cutting temperatures and strain rate at a higher cutting speeds. As a result, this causes plastic deformation of workpiece and required cutting force for machining are decreased. Fig.4 depicts the influence of cutting variables on the torque during machining of AA7039 based MMCs. The power and torque requirements in milling process are also a significant criterion for a stable machining performance. The spindle speeds for milling of metal matrix composites containing harder ceramic particles such as $\mathrm{Al}_{2} \mathrm{O}_{3}, \mathrm{~B}_{4} \mathrm{C}$, and $\mathrm{SiC}$ have a great importance on the availability of adequate power and torque. That is why the effect of milling parameters on the torque was investigated in the milling of composite specimens. From the Fig.4 and mean effect graph in Fig.6, the torques were increased with the increasing axial cutting depth while cutting speed was observed to have insignificant effect on the result of torques in the milling of all composite specimens. The torque values are increased with the amount of removed metal due to the friction force at the cutting edge and chip interface regardless of the workpiece materials. In this study, the torque increased for a cutting feed of 0.17 $\mathrm{mm} /$ tooth while remaining almost constant for cutting feed of $0.1 \mathrm{~mm} /$ tooth and $0.13 \mathrm{~mm} /$ tooth in the milling of composite specimens. The results depicted that the torque was not affected effectively by increasing feed rate. The cutting feed showed a less negative effect on the torque value due to reducing in contact time between the cutting tool and workpiece.

The minimal mean cutting force and torque values are achieved in the milling of AA7309 reinforced with 10 wt.\% $\mathrm{Al}_{2} \mathrm{O}_{3}$ composites among the studied composites. However, the highest cutting force and torque results are measured in the milling of AA7309 reinforced with 10 wt.\% SiC composites. Increasing thrust force and torque can be attributed to the particle distribution in the matrix structure and BUE creation on the insert. A uniform particle distribution was obtained in $\mathrm{Al}_{2} \mathrm{O}_{3}$ reinforced composites with $7.1 \mu \mathrm{m}$ particle size. Although the mixing time was the same, the particle distribution of $\mathrm{B}_{4} \mathrm{C}$ with $3.1 \mu \mathrm{m}$ particle size and $\mathrm{SiC}$ with $4.8 \mu \mathrm{m}$ particle size was not sufficiently homogenous. Small $\mathrm{B}_{4} \mathrm{C}$ and $\mathrm{SiC}$ particles caused to more agglomeration of the particles and hence, some agglomerated particles are observed in the matrix structure [1]. BUE creation was also seen at all machining parameters in the milling of AA7039/ $\mathrm{B}_{4} \mathrm{C}$ and AA7039/SiC composites (Fig.5). These agglomerated particles and BUE formation are negatively affected the cutting tool performance, thrust force and torque.
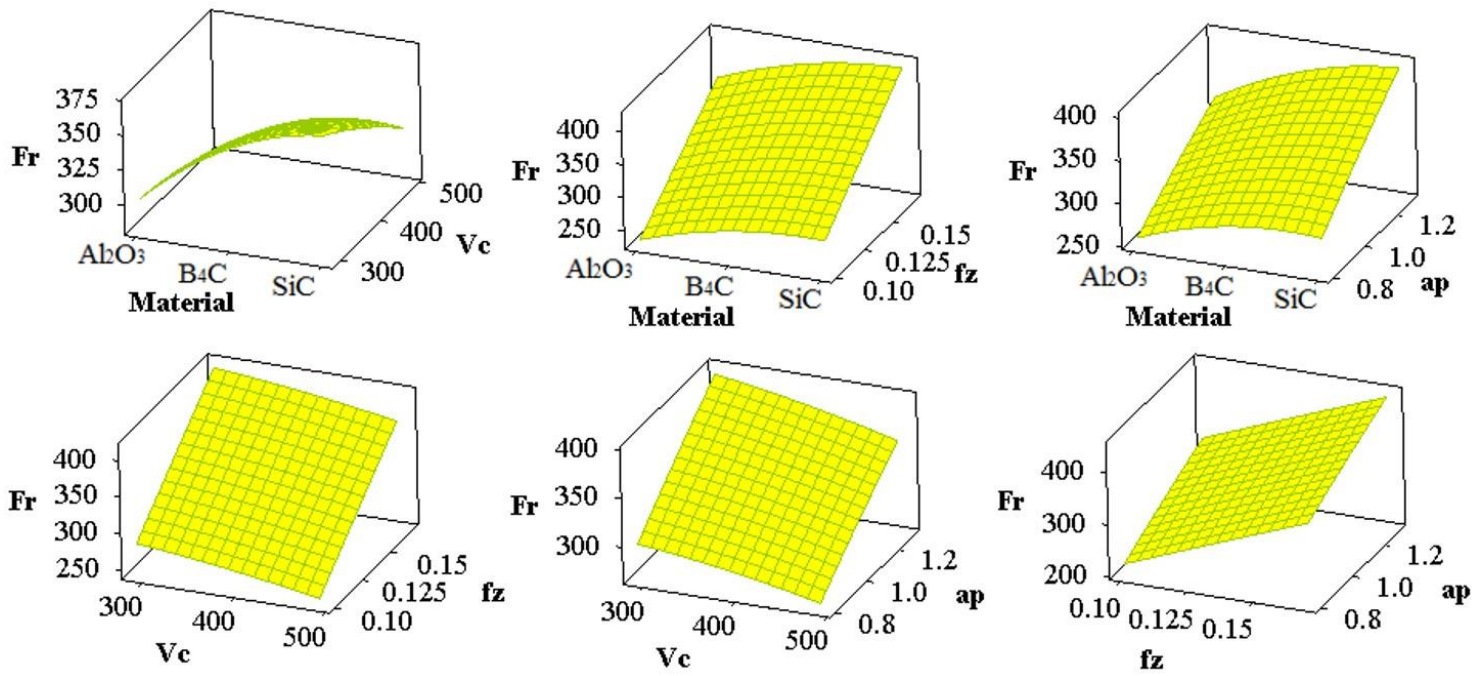

Fig. 3. The effect of the milling parameters on thrust forces in the milling of AA7039 based MMCs 

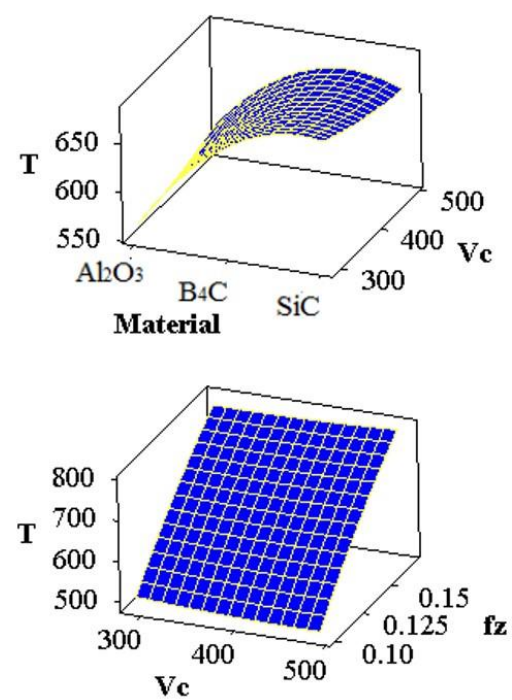
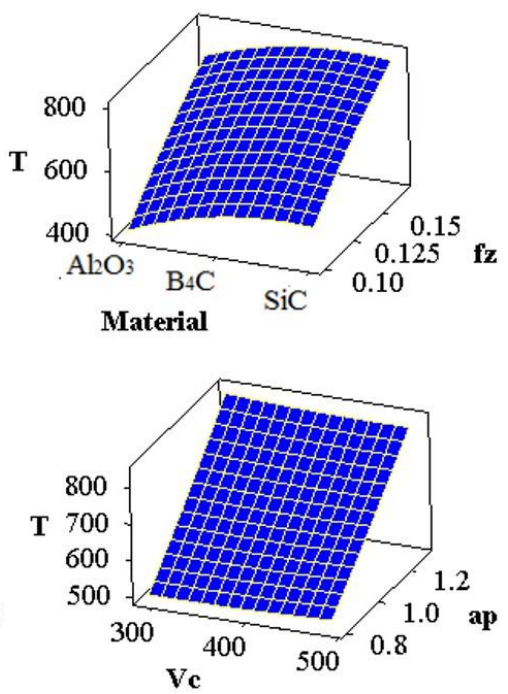
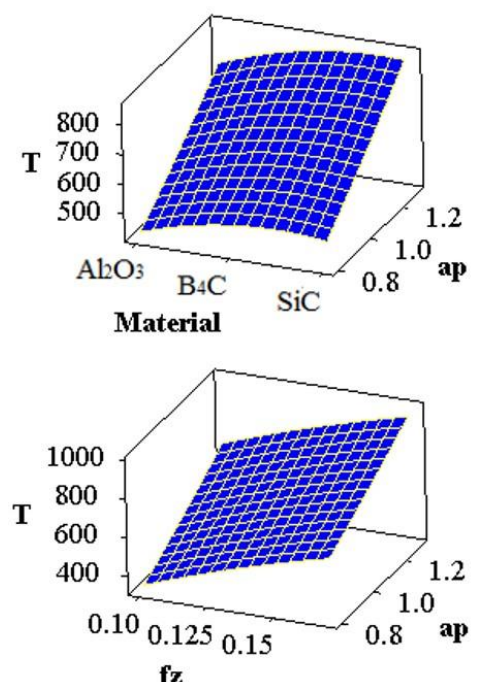

Fig. 4. The effect of the milling parameters on torque in the milling of AA7039 based MMCs
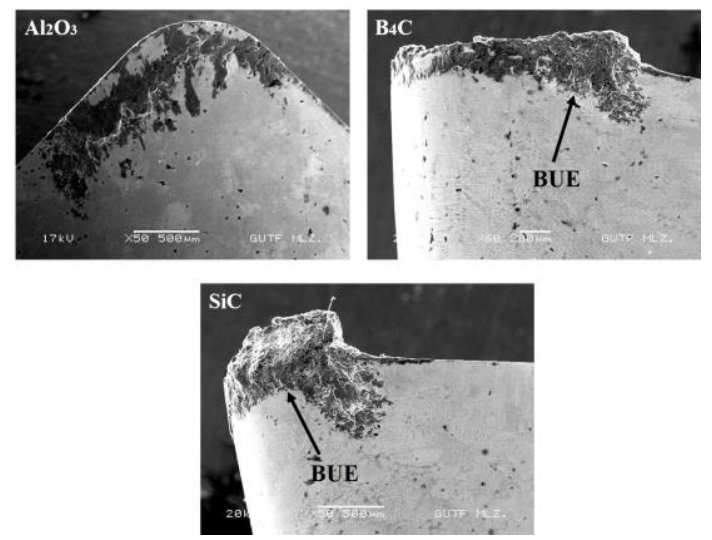

Fig. 5. SEM micrographs of cutting edge used in milling AA7039 based MMCs

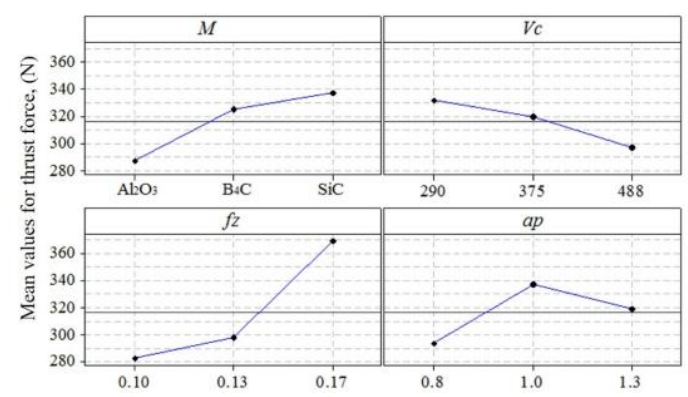

Fig. 6. Effect of cutting parameters on average thrust force

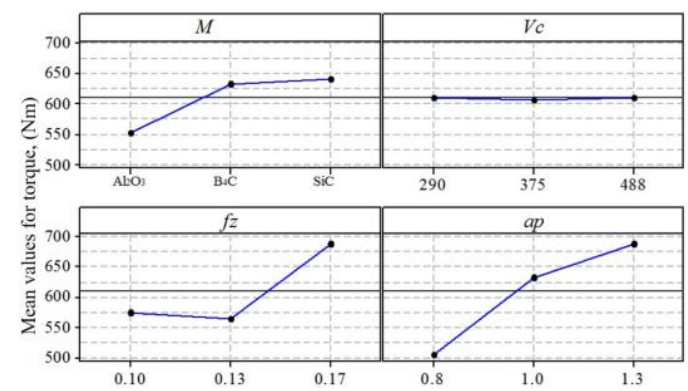

Fig. 7. Effect of cutting parameters on average torque

\subsection{Analysis of Variance (ANOVA)}

Statistical method of linear regression and ANOVA was used to study the relationship among the machining parameters and to analyze which factors most affecting thrust force and torques at the $95 \%$ confidence level. The significant coefficients of cutting parameters on the thrust forces and torques are given in Tables 4 . The percentage of contributing column shows that the cutting feed and depth of cut have a significant influence on the trust force. From the mean effect plot and ANOVA results, the feed rate and cutting depth affected the thrust force $42.67 \% \%$ and $31.98 \%$ respectively, for all composite specimens. The most significant cutting parameters for torque in the milling of three specimens was the axial cutting depth with the percentage contribution of $72.57 \%$. The ANOVA results and mean effect graphs showed that the machining speed has insignificant effect on the cutting force and torque for all experimental specimens and can be neglected. As shown in Figs. 6 and 7, the minimal thrust forces and requirement of lower torque can be achieved by decreasing feed rates and cutting depth and increasing machining speed. Thrust force and torque in milling three metal matrix composites are given below:

$F_{r}=-106.577+25.0195 \times \mathrm{M}-0.1759 \times V_{C}+1922.45 \times f_{z}+178.45 \times a_{p}$

$\mathrm{T}=-672.776+44.965 \times \mathrm{M}-0.00684 \times V_{C}+4025.52 \times f_{Z}+637.156 \times a_{p}$

The adequacy of the linear regression models are confirmed by using the coefficient of correlation, $R^{2}$. The coefficient of correlation values of the equations derived from the regression models for cutting force and torque were computed as $94.59 \%$ and $93.87 \%$ respectively. $R^{2}$ values are indicated that the models are adequate at the $95 \%$ confidence level. 
Table 4. Analysis of Variance for thrust forces

\begin{tabular}{lllllll}
\multicolumn{7}{c}{ Table 4. Analysis of Variance for thrust forces } \\
\hline Source & DF & SS & SS & F & P & $\begin{array}{l}\text { Rate } \\
(\%)\end{array}$ \\
\hline $\begin{array}{l}\text { Thrust } \\
\text { force }\end{array}$ & & & & & & \\
$M$ & 1 & 11267.6 & 11267.6 & 54.537 & 0.0000002 & $13.40 \%$ \\
$V c$ & 1 & 5497.8 & 5497.8 & 26.610 & 0.0000359 & $6.54 \%$ \\
$f z$ & 1 & 35882.2 & 60776.6 & 294.169 & 0.0000000 & $42.67 \%$ \\
$a_{p}$ & 1 & 26891.6 & 26891.6 & 130.160 & 0.0000000 & $31.98 \%$ \\
Error & 22 & 4545.3 & 206.6 & & & $5.41 \%$ \\
Total & 26 & 84084.5 & & & & \\
Torque & & & & & & \\
$M$ & 1 & 36395 & 36395 & 27.638 & 0.000028 & $7.70 \%$ \\
$V c$ & 1 & 8 & 8 & 0.006 & 0.937448 & $0.00 \%$ \\
$f z$ & 1 & 64216 & 266484 & 202.367 & 0.000000 & $13.59 \%$ \\
$a_{p}$ & 1 & 342823 & 342823 & 260.338 & 0.000000 & $72.57 \%$ \\
Error & 22 & 28970 & 1317 & & & $6.13 \%$ \\
Total & 26 & 472412 & & & & \\
\hline
\end{tabular}

\subsection{Artificial Neural Networks for Thrust Force and Torque.}

The experimental results were modelled to predict the cutting force and torque value during milling of AA7039 based MMCs using a multilayer ANN model with feed forward back propagation algorithm. Based on Fig.8, the multilayer feedforward training network with the input, output and hidden layers was applied. The designed neural network expects all input and output values to be between 0 to 1 or -1 to 1 . Hence, in the first step of the network training, the input and output parameters were normalized in $(-1,1)$ using the following equation (3).

$N_{i}=\frac{m_{i}-m_{\min }}{m_{\max }-m_{\min }}$

where

$m_{\mathrm{i}}$ is the input/output data, $m_{\min }$ is the minimum possible value of the input parameters

$m_{\max }$ is the maximum possible value of the input parameters data.

This calculation is done automatically in Pythia software. The type of composite specimens, machining speed, cutting feed and depth of cut were defined as input neurons and the output neurons are thrust force and torque. The network was trained with 21 test data and subsequently confirmed with the 7 experimental data. Three different metal matrix composites specimen were machined in the present experimental study to specify the influence of reinforcement particles on the cutting force and torque. Therefore, the samples are coded minimum 1 and maximum 3 for the artificial network training. The minimum and maximum input parameters used in the experiments for normalization are presented in Table 5. The Pythia software uses the Fermi function as the transfer function using equation (4).

$N_{(i)}=\frac{1}{1+e^{-4\left(E_{i}-0.5\right)}}$

Table 5. Limiting values of the ANN software

\begin{tabular}{lcc}
\hline Inputs & Minimum & Maximum \\
\hline Material $M$ & 1 & 3 \\
Cutting speed $V_{c}$ & 290 & 488 \\
Feed rate $f_{z}$ & 0.1 & 0.17 \\
Axial depth of cut $a_{p}$ & 0.8 & 1.3 \\
\hline
\end{tabular}

The network parameters are processed to optimize the network output values in order to predict fit data. After the training and reproduction phase, the ANN structure was determined with three layers and twelve neurons as show in Fig. 8.

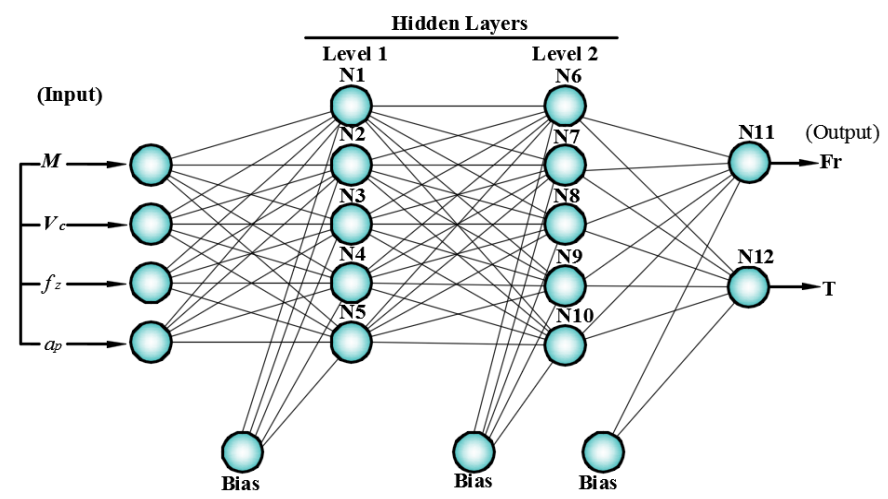

Fig.8 ANN in the Levenberg-Marquardt algorithm structure for the thrust force and torque

Each network input data is connected to every neuron in the first level and the output of each neuron is connected to every neuron in the next level. The calculated weights are presented in Table 6.

The activities of the $N_{I}-N_{5}$ are calculated as;

$E_{i}=w_{1 i} * M+w_{2 i} * V_{c}+w_{3 i} * f_{z}+w_{4 i} * a_{p}$

Where,

$E_{\mathrm{i}}$ is the activities of the neurons,

$i$ is the number of inputs,

$w_{\mathrm{i}}$ is the neurons weights

The outputs of $N_{1}-N_{5}$ are calculated as

$N_{(i)}=\frac{1}{1+e^{-4\left(E_{i}-0.5\right)}}$

$E_{i}=w_{1 i} * N_{1}+w_{2 i} * N_{2}+w_{3 i} * N_{3}+w_{4 i} * N_{4}+w_{5 i} * N_{5}$

Table 6. Weight values used in Equation 6

\begin{tabular}{|c|c|c|c|c|}
\hline \multirow[t]{2}{*}{ i } & \multicolumn{3}{|c|}{ weights for thrust force } & \multirow[b]{2}{*}{$\mathrm{W}_{4 \mathrm{i}}$} \\
\hline & $\mathrm{W}_{1 \mathrm{i}}$ & $\mathrm{W}_{2 \mathrm{i}}$ & $\mathrm{W}_{3 \mathrm{i}}$ & \\
\hline 1.1 & -0.641615 & 0.964341 & -0.674801 & -0.710380 \\
\hline 1.2 & 0.453339 & 1.064664 & -0.923088 & -0.975535 \\
\hline 1.3 & -0.018847 & 0.724369 & 0.595416 & -2.019125 \\
\hline 1.4 & 0.565030 & 0.720068 & 0.131456 & -0.125667 \\
\hline 1.5 & 0.347206 & 0.898850 & 0.569796 & -1.219484 \\
\hline \multirow[t]{2}{*}{$\mathrm{i}$} & \multicolumn{4}{|c|}{ weights for torque } \\
\hline & $\mathrm{W}_{1 \mathrm{i}}$ & $\mathrm{W}_{2 \mathrm{i}}$ & $\mathrm{W}_{3 \mathrm{i}}$ & $\mathrm{W}_{4 \mathrm{i}}$ \\
\hline 1.1 & -0.613107 & 0.798307 & -0.587410 & -1.104612 \\
\hline 1.2 & 0.738065 & 1.316772 & -1.965709 & -1.741744 \\
\hline 1.3 & 0.486763 & -0.146797 & -0.236760 & -1.546769 \\
\hline 1.4 & 0.542935 & 0.484263 & 0.424082 & -0.118507 \\
\hline 1.5 & 0.448045 & 0.245691 & 0.602117 & -1.659422 \\
\hline
\end{tabular}

Similarly, the activities of the N6 to N10 are computed using equation (8). The computed weights are presented in Table 7. The network is processed from left to right and the outputs of $N_{1}-N_{5}$ are the inputs for the computation of $N_{6}$ to $N_{10}$. 
Table 7. Weight values used in Equation 7

\begin{tabular}{|c|c|c|c|c|c|}
\hline \multirow[t]{2}{*}{$i$} & \multicolumn{5}{|c|}{ weights for thrust force } \\
\hline & $\mathrm{W}_{1 i}$ & $\mathrm{~W}_{2 i}$ & $\mathrm{~W}_{3 i}$ & $\mathrm{~W}_{4 i}$ & $\mathrm{w}_{5 i}$ \\
\hline 2.6 & 1.308292 & 0.254031 & -0.155567 & -0.707301 & 0.345201 \\
\hline 2.7 & 1.325259 & -0.207788 & 0.591904 & 1.635325 & -2.048602 \\
\hline 2.8 & -0.621627 & -1.382413 & -1.911599 & 1.964388 & -1.074672 \\
\hline 2.9 & 0.327757 & -0.060671 & 0.689212 & -1.811071 & 0.842268 \\
\hline 2.10 & -1.389981 & -0.551511 & -0.153293 & 0.385712 & 0.757761 \\
\hline \multirow[t]{2}{*}{$l$} & \multicolumn{5}{|c|}{ weights for torque } \\
\hline & $\mathrm{W}_{1 i}$ & $\mathrm{~W}_{2 i}$ & $\mathrm{~W}_{3 i}$ & $\mathrm{~W}_{4 i}$ & $\mathrm{~W}_{5 i}$ \\
\hline 2.6 & 3.559735 & 0.010124 & 0.224909 & -0.088282 & -0.439165 \\
\hline 2.7 & 0.164152 & -0.502624 & -0.512776 & 0.068015 & -1.182625 \\
\hline 2.8 & -1.451413 & -1.694781 & -1.549240 & 0.321606 & -1.007977 \\
\hline 2.9 & 0.424412 & -0.019804 & 0.978870 & -0.938918 & 1.386686 \\
\hline 2.10 & -1.634803 & -0.140478 & -0.178953 & 0.698680 & 0.625789 \\
\hline
\end{tabular}

The analytical models were generated with the weight values in Tables 7 and 8 so as to predict the cutting force and torque. The following equations ( 8 and 9) were derived using the weight values of the neurons in the ANN network structure with the given milling parameters. These prediction models can be used for the prediction of the thrust force and torque in the milling of AA7039 based MMCs using the uncoated carbide inserts.

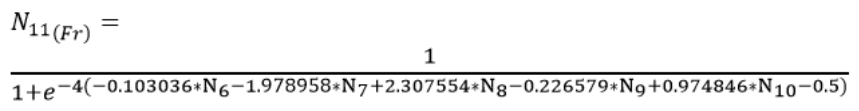

(8)

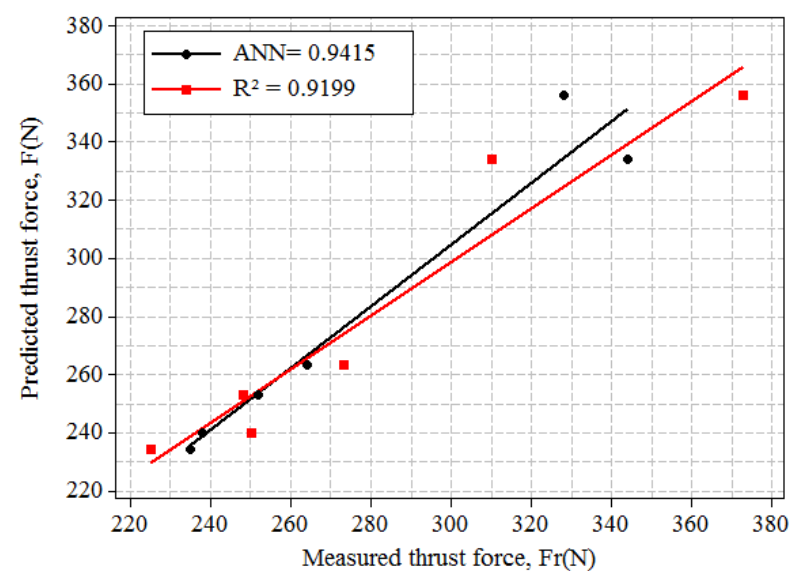

Fig. 9. Confirmation test results of ANN and regression model for experimental outputs

\section{Conclusion}

This study investigated the influences of the $\mathrm{B}_{4} \mathrm{C}, \mathrm{Al}_{2} \mathrm{O}_{3}$ and $\mathrm{SiC}$ reinforcement particles in the AA7039 matrix and cutting parameters on thrust force and torque in the milling process. Mathematical models of thrust force and torque were generated using an ANN and regression analysis. The test results were also analyzed using ANOVA. The experimental results can be summarized as follow:

- Three AA7039 composite specimens reinforced with 10 wt. $\% \quad \mathrm{~B}_{4} \mathrm{C}, 10$ wt. $\% \quad \mathrm{Al}_{2} \mathrm{O}_{3}$, and 10 wt.\% $\mathrm{SiC}$ were successfully fabricated through a powder metallurgy and hot extrusion route. The reinforced particles are generally uniformly distributed in the matrix but some agglomerations were observed in AA7039 reinforced with $\mathrm{SiC}$ andB ${ }_{4} \mathrm{C}$.

$$
\begin{aligned}
& N_{12(T)}= \\
& \frac{1}{1+e^{-4\left(-2.443297 * \mathrm{~N}_{6}+1.453050 * \mathrm{~N}_{7}+3.432468 * \mathrm{~N}_{8}-0.466388 * \mathrm{~N}_{9}+0.918279 * \mathrm{~N}_{10}-0.5\right)}}
\end{aligned}
$$

ANN and regression equations were confirmed by performing the confirmation experiments. the verification experiments were conducted at random intermediate values of cutting parameters, and the comparison of the validation test results and estimated values were depicted in Fig.9. Prediction accuracy of the ANN model equations for $\mathrm{Fr}$ and $T$ were computed as $94.15 \%$ and $94.88 \%$ respectively. $R^{2}$ values of the equations derived from the regression model for $F r$ and $T$ were calculated as $91.9 \%$ and $92.2 \%$ respectively. The confirmation experiment results showed that the ANN model has been successfully employed to the machining variables of milling AA 7039 based composites. Figs. 9 depict the estimated values obtained from regression and ANN models and confirmation test results. ANN models have shown a good agreement between the estimated and experimental results and the developed equations were also successful at predicting the cutting force and torque in the milling of AA7039 based MMCs.

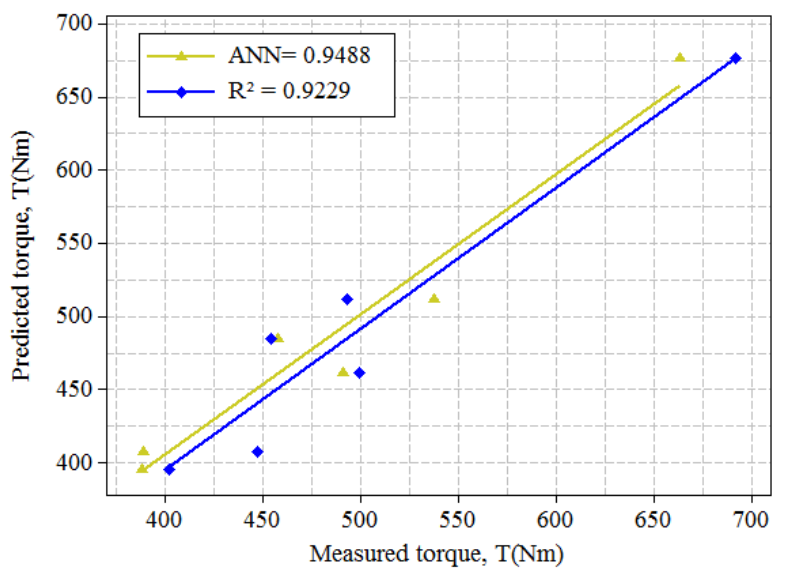

- The lower thrust force and requirement of torque were achieved during milling of AA7039 reinforced $\mathrm{Al}_{2} \mathrm{O}_{3}$ composite specimens. Well distributed $\mathrm{Al}_{2} \mathrm{O}_{3}$ particles in the matrix remarkably decreased the BUE creation, cutting force and torque.

- The optimal machining parameters for cutting force and torque were determined at the lowest cutting feed, depth of cut and the highest machining speed for all composite specimens.

- The cutting feed was the most effective machining parameters for thrust force with a percentage contribution of $42.67 \% \%$ and followed by the axial cutting depth with the percentage contribution of $31.98 \%$.

- The most effective machining parameters for torque was the axial cutting depth with the percentage contribution of $72.57 \%$ during milling of experimental specimens.

- From the ANOVA results and mean effect plots, the cutting speed was not presented to have a significant 
correlation on the thrust force and torque in the milling of composites.

- The generated ANN models indicated a good agreement with determination coefficients for thrust force and torque $R^{2}=94.15 \%$ and $94.88 \%$, respectively.

These results depicted that ANNs can be used successfully for the estimation of thrust force and torque in the milling of AA7039 based metal matrix composites.

\section{Acknowledgments}

The author would like to thanks to Hacettepe University Scientific Research Projects Coordination Unit for supporting to this research work through the Scientific Research Projects Grant funding number \# 014 D05 603 001-636.

\section{References}

[1] Ş. Karabulut, U. Gökmen and H. Çinici, "Study on the mechanical and drilling properties of AA7039 composites reinforced with $\mathrm{Al}_{2} \mathrm{O}_{3} / \mathrm{B}_{4} \mathrm{C} / \mathrm{SiC}$ particles", Compos. Part. B, vol. 93, pp. 43-55, May 2016.

[2] K. Umanath, K. Palanikumar and ST. Selvamani, "Composites: Part B Analysis of dry sliding wear behaviour of $\mathrm{Al} 6061 / \mathrm{SiC}_{\mathrm{Al}} \mathrm{O}_{3}$ hybrid metal matrix composites", Compos Part B, vol. 53, pp. 159-68, October 2013.

[3] Ş. Karabulut, "Optimization of surface roughness and cutting force during AA7039/ $\mathrm{Al}_{2} \mathrm{O}_{3}$ metal matrix composites milling using neural networks and Taguchi method" Measurement, vol. 66, pp. 139-149, April 2015.

[4] E. Budak, "Analytical models for high performance milling. Part I: Cutting forces, structural deformations and tolerance integrity”, Int. J. Mach. Tools Manuf, vol. 46, no. 12, pp. 1478-1488, October 2006.

[5] H. Saglam, S. Yaldiz and F. Unsacar, "The effect of tool geometry and cutting speed on main cutting force and tool tip temperature", Mater. Des., vol. 28, no. 1, pp. 101111, 2007.

[6] M.E. Merchant, "Basic mechanics of the metal cutting process", ASME J. Appl. Mech, vol. 66, pp. 168-175, 1944.

[7] E.H. Lee and B.W. Shaffer, "The theory of plasticity applied to a problem of machining", ASME Trans. J. Appl. Mech., vol. 18, pp. 405-413, 1951.

[8] S. Kannan, H.A. Kishawy and I. Deiab, "Cutting forces and TEM analysis of the generated surface during machining metal matrix composites", J. Mater. Process. Technol, vol. 209, no. 5, pp. 2260-2269, 2009.

[9] Y. Ozcatalbas, "Investigation of the machinability behaviour of $\mathrm{Al}_{4} \mathrm{C}_{3}$ reinforced Al-based composite produced by mechanical alloying technique", Compos. Sci. Technol., vol. 63, no. 1, pp. 53-61, 2003.

[10]K. Palanikumar and A. Muniaraj, "Experimental investigation and analysis of thrust force in drilling cast hybrid metal matrix (Al-15\% SiC-4\%graphite) composites", Measurement, vol. 53, pp. 240-250, 2014.

[11]J.T. Lin, D. Bhattacharyya and C. Lane, "Machinability of a silicon carbide reinforced aluminium metal matrix composite", Wear, vol. 181, pp. 883-888, 1995.

[12] A. Manna, B. Bhattacharayya, "A study on machinability of $\mathrm{Al}=\mathrm{SiC}-\mathrm{MMC}$ " J. Mater. Process. Technol, vol. 140, no. 1, pp. 711-716, 2003.

[13] M. El-Gallab and M. Sklad, "Machining of Al/SiC particulate metal matrix composites: part II: workpiece surface integrity", J. Mater. Process. Technol, vol. 83, no. 1, pp. 277-285, 1998.

[14] Ş. Karabulut, H. Çinici and H. Karakoç, "Experimental Investigation and Optimization of Cutting Force and Tool Wear in Milling Al7075 and Open-Cell SiC Foam Composite", AJSE-Engineering., vol. 41, pp. 1797-1812, 2016.

[15]B. Das, S. Roy, R.N. Rai and S.C. Saha, "Study on machinability of in situ $\mathrm{Al}-4.5 \% \mathrm{Cu}-\mathrm{TiC}$ metal matrix composite-surface finish, cutting force prediction using ANN", CIRP J. Manuf. Sci. Technol., vol 12, pp. 67-78, 2016.

[16]Ş. Karabulut, A. Güllü, "Farklı yanaşma açıları ile vermiküler grafitli dökme demirin frezelenmesinde kesme kuvvetlerinin araştırılması ve analitik modellenmesi”, Gazi Üniv. Müh. Mim. Fak. Der., vol. 28 1, pp. 135-143, 2013.

[17] V. Hiremath, P. Badiger, V. Auradi, S.T. Dundur and S.A. Kori, "Influence of particle size on Cutting Forces and Surface Roughness in Machining of $\mathrm{B}_{4} \mathrm{Cp}-6061$ Aluminium Matrix Composites", In IOP Conference Series: Materials Science and Engineering, vol. 114, pp. 012041 , February 2016.

[18] M.T. Hayajneh, A.M. Hassan and A.T. Mayyas, "Artificial neural network modeling of the drilling process of self-lubricated aluminum/alumina/graphite hybrid composites synthesized by powder metallurgy technique", J. Alloys Compd., vol. 478, no. 1, pp. 559565, 2009. 